\title{
Responsabilidade do Funcionário Público
}

\author{
Clenício da Silva Duarte
}

Consultor Jurídico do DASP

SUMARIO: 1. Tríplice responsabilidade pelo exercício irregular da função pública. Independência das instâncias e possibilidade de cumulação de cominações. 2. Responsabilidade civil do funcionário. Dano direto e indireto. 3. Responsabilidade civil das pessoas jurídicas de direito público pelo dano que os seus agentes, nessa qualidade, causem a terceiros. Evolução legislativa e jurisprudencial. 4. Conceito de funcionário, para fins de responsabilidade civil decorrente de ato ilicito praticado no exercício de suas funções e na qualidade de funcionário. 5. Responsabilidade civil das pessoas jurídicas de direito público como matéria de Direito Administrativo. 6. O extraordinário desenvolvimento dado pela doutrina e jurisprudência à responsabilidade civil. 7. A teoria do risco administrativo adotada pelo direito brasileiro. 8 . O sujeito passivo da ação de indenizaçăo a ser proposta pela vítima. 9. Causas excludentes de responsabilidade da pessoa jurídica de direito público. 10. Ação regressiva contra o funcionário causador do dano; seus pressupostos; sua execução. 11. Responsabilidade penal do funcionário. Conseqüência de sua condenação. 12. Efeitos da decisão criminal na responsabilidade civil e na ação disciplinar. 13. Responsabilidade administrativa. Direito Disciplinar. Princípios que o informam. 14. Processo administrativo e sua revisão. Fases do processo administrativo. Consequeências do provimento da revisão requerida.

1. O Estatuto dos Funcionários Públicos Civis da União ${ }^{1}$, no Capítulo IV do seu Título IV (arts. 196 a 200), estabelece as regras de responsabilidade atinentes aos seus destinatários, começando por indicá-las, ${ }^{2}$ para, em seguida, esboçar-lhes a conceituação, ${ }^{3}$ em seu tríplice aspecto: civil, penal e administrativo. 
Essa tripla responsabilidade a que o funcionário está sujeito é apurada separadamente, de acordo com a natureza da falta cometida, podendo, se o exercício irregular de que se trate importar em prática de ilícito civil e penal, concomitantemente com o administrativo, aplicar-se cumulativamente, pelo mesmo fato, sanção civil, penal e disciplinar. Esse princípio da independência das instâncias civil, penal e administrativa está consagrado no art. 200 do citado Estatuto. ${ }^{4}$

2. A responsabilidade civil do funcionário é sempre proveniente de um prejuízo causado à Fazenda Pública, ou pelo dano direto ${ }^{5}$ a esta infligido pelo agente administrativo, ou pelo indireto, imediatamente acarretado a terceiros, mas por cuja indenização, nos termos constitucionais, ${ }^{6}$ responde a pessoa jurídica de direito público, que só se ressarcirá se tiver o funcionário agido com culpa lato sensu, mediante a competente ação regressiva, a ser intentada após a indenização do lesado. Por esse efeito, padece de imprecisão vocabular a conceituação legal $^{7}$ de responsabilidade civil, que se refere, alternadamente, a dano causado à Fazenda Nacional ou a terceiros, quando o dano, em qualquer hipótese, é sempre infligido à Fazenda Pública, que, mesmo no caso de lesão de terceiros, assume, de logo e diretamente, a responsabilidade da reparação, para ressarcir-se mais tarde, com a procedência da ação regressiva a ser ajuizada após a indenização do dano à vítima.

No caso de dano direto à entidade de direito público, a questão é mais simples, porquanto a responsabilidade civil é promovida pela pessoa jurídica lesada, através da ação ordinária ${ }^{8}$ respectiva, bastando comprovar-se o montante do dano, a relação de causalidade e respectiva autoria, bem como a efetiva ação ou omissão dolosa ou culposa do agente. A indenização, se excedente às forças da fiança (no caso, evidentemente, de funcionário afiançado) e inexistindo bens que respondam, poderá ser liquidada mediante o desconto em prestações mensais não-excedentes da décima parte do vencimento ou remuneração (Estatuto, art. $97, \S 1 .^{\circ}$ ). Fica entendido que essa indenização, a

4 Veja-se a redação do precelto legal mencionado: "As cominaçð̄es civis, penais e disas instancias civil, penalar-se, sendo umas e outras independentes entre si, bem assim

5 Por exemplo civil, penal e administrativa".

viatura oficial, ou causa, doná, por imprudéncia, negligência ou imperícia, danifica uma Pública.

6 Constituiga de 1969.

7 Art. 197, caput.

8 Nunca ocorreria a hipstese de - dano administrativamente de açăo executiva, pois jamais seria possivel considerar-se imporia, com a ação, năo só comprovar divida liquida e certa, dado que sempre se ação culposa (em sentido lato) do réu. montante da reparaçắo como a autoria e a 
menos que o funcionário concorde, só poderá ser promovida como execução de sentença, em ação julgada procedente que a entidade pública houver ajuizado contra o funcionário.

No que concerne ao dano causado diretamente a terceiros, em que se vincula, não obstante, a responsabilidade da pessoa jurídica de direito publico, que só se exonera da respectiva reparação em casos especiais, que serão esclarecidos mais adiante, a responsabilidade civil do funcionário é apurada, como já se mencionou, em ação regressiva, quando se terá de comprovar que $o$ ato danoso decorreu de ação ou omissão sua, de natureza culposa (lato sensu).

3. Se a responsabilidade civil do Estado atualmente não tem mais opositores, nem sempre foi assim. Como assinalam CARLOS GARCIA OVIEDO e ENRIQUE MARTINEZ USEROS, ${ }^{9}$

"El problema de la responsabilidad de la Administración es moderno. En otros tiempos, su mero planteamiento hubiese sido tratado de sacrilegio político. Los termos soberania y responsabilidad se excluían. Los daños ocasionados a los particulares por actos del Estado debian ser sufridos por aquéllos como mal mayor, consecuencia de su vida político-social. Respondían, a lo sumo, los funcionarios, no el Estado.

Pero el moderno Estado de Derecho, que somete el Poder a la legalidad por él mismo establecida, ha derivado la juridicidad de la Administración y, con más amplia perspectiva, la impresión en la actividad de la misma de un fundamental sentido ético".

Regia, assim, primitivamente, o princípio da irresponsabilidade do Estado, que só excepcionalmente, e em razão de lei expressa, é que se autorizava o particular a obter-lhe uma indenização. ${ }^{10}$

Dessa irresponsabilidade total, que se estendia até ao agente administrativo causador do dano, evoluiu-se para a responsa-

9 Derecho Administrativo, 9. a ed., Madrid, 1968, vol. III, ps. 719 e 720.

10 "Pendant longtemps, ces dommages, à part quelques exceptions légales, n'entraînaient point des responsabilités, à la charge des personnes administratives, et, il y a quarante ans, Laferrière, dans son traité de La juridiction administrative et des recours contentieux, pouvait écrire que "le propre de la souveraineté est de s'imposer à tous sans compensations".

Aujourd'hui, ce principe, grace surtout à l'oeuvre du Conseil d'Etat, peut être consideré comme renversé: les administrations publiques sont, d'une façon générale, responsables des conséquences dommageables de leur activité" (MAURICE HAURIOU, Précis Elémentaire de Droit Administratif, 4.a ed., Paris, Sirey, 1937, atualizada por André Hauriou). 
bilidade tão-somente do funcionário, quando sua ação decorria de dolo ou culpa, passando-se à responsabilidade solidária e, num estágio mais avançado, à responsabilidade direta do Estado, provada a culpa do agente, que respondia depois perante a administração, para, finalmente, chegar-se à responsabilidade objetiva da pessoa jurídica de direito público, independentemente de atuação culposa do funcionário, o qual, se comprovado o elemento subjetivo, ressarciria o dano reparado após a competente ação regressiva.

No Direito Constitucional brasileiro, a matéria sofreu a seguinte evolução: A Constituição do Império, de 1824 , ${ }^{11}$ estabelecia a responsabilidade dos empregados públicos, pelos abusos e omissões praticados no exercício de suas funções, inclusive em não promover a responsabilidade dos infratores, seus subordinados, mas essa responsabilidade só se efetivava perante a administração, sem que se dispusesse sobre a responsabilidade por danos causados a terceiros.

Em termos equivalentes, dispôs a primeira Constituição da a irresponsabilidade do Estado. Entretanto, a jurisprudência, se, a princípio, negava-se a admitir, em razão do texto, a responsabilidade do Estado pelo dano que seus funcionários causassem a terceiros, passou a reconhecê-la, ressalvando-se-lhe o direito regressivo contra os seus agentes, por abusos e omissões. ${ }^{13}$

Com a Constituição de 1934, assim como com a Carta Política de 1937, adotou-se a responsabilidade solidária entre o funcionário e a Fazenda Pública, estatuindo a primeira delas, expressamente, o litisconsórcio necessário do agente, que assim seria, com a execuçãa da sentença contra a Fazenda, também
por esta executado. ${ }^{14}$

11 Dispunha o $\S 29$ do art. 179: "Os empregados públicos săo estritamente responsáveis efetivamentes $e$ omissōes praticados no exercicio das suas funçōes, $\theta$ por năo fazerem

12 "Art. 82. Os funcioneis aos infratores".

omissões em que incorrerem públicos săo estritamente responsáveis pelos abusos e ou negligência em năo responsabilicicio de seus cargos, assim como pela indulgência Parágrafo único. O funcionário públizetivamente os seus subalternos.

13 af da posse, ao desempenho dos seus obrigar-se-á por compromisso formal, no Cf., ao propósito, JOĀO BARBALHO seus deveres".

14 Constituiro, 1924 , ps. 485 e 486

Rrasileira, 2. a ed., Rio de

com a Fazenda Nacional 171: “Os funcionários públicos săo responsáveis solidariamente de negligência, omissão ou abusal ou municipal, por quaisquer prejuizos decorrentes proposta contra a Fazenda púbuso no exercicio dos seus cargos". § 1.0 : "Na açăo será sempre citado como litisconsor e fundada em lesăo praticada por funcionário, este esta promoverá execuçảo contra Constituiçăo de 1937, art. 158. "O funcionário público".

riamente com a Fazenda nacional "Os funcionários públicos săo responsáveis solidarentes de negligência, omissăo ou abuso ou municipal, por quaisquer prejuizos decor- 
As Constituições de $1946^{15}$ e $1967^{16}$ substituíram o princípio da responsabilidade solidária pelo da regressividade. Por este, a pessoa jurídica de direito público responde diretamente pelo dano civil, para somente responsabilizar o funcionário se agiu ele com dolo ou culpa, não havendo, em conseqüência, litisconsórcio necessário, como se impunha no da responsabilidade solidária das Constituições de 1934 e 1937.

4. Convém observar-se que o conceito de funcionário, para fins de responsabilidade civil, é tomado em sentido amplíssimo, abrangendo não só os servidores públicos, civis e militares, como quaisquer pessoas, percebam ou não remuneração, que se possam considerar como agentes da pessoa jurídica de direito público de que se trate. ${ }^{17}$

5. Como bem adverte AGUIAR DIAS, ${ }^{18}$ não há pretender disciplinar a responsabilidade civil do Estado pelo Código Civil, porquanto é tipicamente matéria de Direito Administrativo. E o Estado - acrescenta o eminente jurista - "não está para o funcionário como o preponente para o preposto, o patrão para o empregado. Não seria acertado compreender as relações do funcionário com o Estado como contratuais, e hoje ninguém mais incorre em tal equívoco". 19

15 Art. 194: "As pessoas jurídicas de direito público interno são civilmente responsáveis pelos danos que os seus funcionários, nessa qualidade, causem a terceiros". Parágrafo único: "Caber-lhes-á açăo regressiva contra os funcionários causadores do dano, quando tiver havido culpa destes".

16 A redaçăo primitiva (art. 105) é quase idêntica à atual, decorrente da Emenda Constitucional n.o 1, de 1969 (art. 107), apenas mudando-se o tempo de dois verbos. Assim, onde se dizia: "respondem" e "causem", diz-se, agora, "responderăo" e "causarem". Como se vê, o comando jurídico é o mesmo. Confira-se a redaçăo em vigor: Art. 107: "As pessoas jurídicas de direito público responderăo pelos danos que seus funcionários, nessa qualidade, causarem a terceiros". Parágrafo único: "Caberá ação regressiva contra o funcionário responsável, nos casos de culpa ou dolo".

17 Cf. Lei n.0 4.619, de 28.IV.1965, art. 1.०, parágrafo único. PONTES DE MIRANDA, Comentários à Constituiçăo de 1967, Rev. dos Tribunais, Săo Paulo, 1967, vol. III, p. 520, ao propósito, assim se expressa: "Critério estritamente objetivo e, portanto, mais largo, exige que se considerem funcionários públicos no art. 105 todos os que praticaram atos, ou incorreram em omissăo, no exercicio de funçăo, sem se dever entrar, sequer, na apuraçăo da legalidade ou ilegalidade da investitudra. Se o Diretor da repartiçăo, ocorrendo falta de funcionários públicos, ou de empregados contratados regularmente, chama ao serviço pessoa que năo é funcionário público, nem regularmente contratada, - essa pessoa causa prejuizos, decorrentes de negligência, omissăo ou abuso, no exercicio do cargo, que acidentalmente the fol entregue, responde - com base no art. 105 - a Fazenda Pública, nacional, estadual ou municipal".

Ressalve-se, no texto transcrito, apenas a afirmativa, evidentemente equivoca, de que o funcionário de fato, para a obrigaçăo de indenizar do Estado, teria de agir com culpa, quando o elemento subjetivo (dolo ou culpa) do funcionário só se leva em conta para efeito da ação regressiva do Estado contra o agente causador do dano. Ainda que este năo houvesse agido com dolo ou culpa, sendo a falta tăo-somente do serviço, responderia o Estado, quer pela teoria clássica (subjetiva), quer pela do risco administrativo (objetiva).

18 JOSÉ DE AGUIAR DIAS, Da Responsabilidade Civil, 2. a ed., Forense, 1950, vol. II, n. 0 197, p. 161.

19 Ob. e vol. cits., n. ${ }^{\circ}$ 201, p. 174. 
6. Na interminável disputa ${ }^{20}$ até hoje mantida pelos defensores da teoria clássica, que se recusam a admitir responsabilidade sem culpa, não obstante as inúmeras exceções introduzidas pela legislação de todos os países, e que não podem obscurecer, e os adeptos da teoria objetiva, evidencia-se o extraordinário desenvolvimento que foi dado à responsabilidade civil contratual e extracontratual, ${ }^{21}$ quer no campo do direito privado, quer na esfera de atuação do direito público, onde parece vitoriosa a teoria do risco administrativo. Mesmo para os que teimam em só reconhecer a responsabilidade civil do Estado, em relação a terceiros, quando tenha ocorrido culpa do funcionário ou do serviço, ${ }^{22}$ um grande passo foi dado em benefício da vítima, ${ }^{23}$ vinculando-se a responsabilidade direta do Estado, que, na hipótese de dolo ou culpa de seu agente, dele ressarcirá o dano reparado através do direito de regresso, só arcando com essa indenização, sem possibilidade de ressarcimento, no caso de culpa do serviço em razão do risco administrativo (na teoria objetiva), ou na hipótese de insolvência do funcionário, culpado direto pelo dano causado.

20 Vejam-se as criticas formuladas à teoria do risco e a sua defesa, na excelente monografia de ALVINO LIMA (Culpa e Risco, Revista dos Tribunais, Săo Paulo, 1960, n. Os 33
e 34, ps. 202-216).

21 A responsabilidad

ou simplesmente do ris contratual, quer extracontratual, pode decorrer de dolo, culpa, Tanto na culpa risco criado com o ato realizado pelo autor do dano. diferença entre ambos, (stricto sensu), como no dolo, há a vontade de realizar o ato. A per atti legittimi della como assinala GIOVANNI SALEMI (La cosi detta responsabilità Enciclopédico do Direito Brasileiro verione, n. $0^{\circ} 24, p .46$, apud AGUIAR DIAS, Repertório no dolo a vonta Direito Brasileiro, verbete Culpa (Civil), n. $\left.{ }^{\circ} 4\right)$, está em que, "enquanto culpa, a vontade se limita prolonga à realizaçăo do efeito nocivo, emergente do ato, na se estender ade se limita ao exercício do ato querido e apreciado como legítimo, sem RENÉ SAVA suas conseqüências".

1951, Tomo I, n. 04, p 5 ) de la Responsabilité Civile en Droit Français, 2.a ed., Paris, l'agent pouvait n. 4, p. 5) define a culpa como sendo "l'inexécution d'une devoir que violé, il y a délit civil, et observer. S'il le connaissait effectivement et l'a delibérement devoir, tout en délit civil, ou, en matière de contrat, dol contractuel. Si la violation du et, en dehors des matières connue et evitée, a été involontaire, il y a faute simple: Dans tous les domaines, contractuelles, on l'appelle quasi-délit.

devoir violé, l'autremaines, la faute comporte deux éléments, l'un surtout objectif, le A responsabilidade civil subjectif, l'imputabilité à l'agent".

ocorre com a violaçăo civil pode ser contratual ou extraconratual. No primeiro caso, privado; no segundoăo de um cláusula, explícita ou implicita, de um contrato público ou stricto sensu), ou em decorrênito, quer delito (quando há dolo), quer quase-delito (culpa "delito é a violaço decorrência do risco criado, independentemente de culpa. Se o "o fato pelo qual a pessoa capaz da norma de conduta", entende-se por quase-delito gência năo-escusável, em rea capaz de ofender, operando sem malícia, mas com negli(AGUIAR DIAS, Repert, relaçăo ao direito alheio, comete infraçăo prejudicial a outrem" Repert, cit., n.० 2).

serviço em trés espécies: Civ., cit., vol. II, n.0 202, p. 176) classifica as faltas ao serviço; c) tardio funcionamento funcionamento do serviço; b) não-funcionamento do sitivos culposos funcionamento do serviço. "Na primeira categoria, estăo os atos potrativa, quando o serviço estava. Na segunda, os fatos conseqüentes à inaçăo adminisrosamente uma ilegriço estava obrigado a agir, embora a inércia năo constitua rigo-

23 "A teoria da culpa, tal, pelo terceira, as conseqüências da lentidăo administrativa". controvérsia, responde aos interesses, como fol ela compreendida no curso de nossa que sofrem as consegüên interesses do que age; a teoria do risco toma a defesa dos la Responsabilité, Presses Universita açăo" (LÉON HUSSON, Les Transformations de 
7. Embora pudesse parecer, à primeira vista, que a norma constitucional brasileira, ao limitar o cabimento da ação regressiva contra o funcionário causador do dano à hipótese de ação ou omissão culposa deste, estaria, a contrario sensu, consagrando a teoria do risco administrativo, do momento em que se reconhecia, assim, a obrigação de indenizar independentemente de culpa do autor direto do dano, a conclusão, tão-só por esse efeito, seria apressada. De fato, ainda que inexistisse culpa do agente, o mesmo poderia não-ocorrer no que concerne a faltas do serviço público, como, por exemplo, o seu mau funcionamento, ${ }^{24}$ que caracterizaria ato culposo da administração, embora não do funcionário que, em razão dessa deficiência, praticou 0 ato de que resultou a obrigação de indenizar.

A culpa lato sensu pode verificar-se: a) por falta do serviço; b) por falta funcional; c) por falta pessoal. Nos dois primeiros casos, é irretorquível a responsabilidade da pessoa jurídica de direito público; no último, só o agente causador do dano é responsável, porque a falta não foi cometida na condição de funcionário, isentando-se a pessoa jurídica de direito público empregadora da obrigação de reparar o dano.

Assim, pois, a norma constitucional (art. 107) não leva, necessariamente, à teoria do risco administrativo, sendo conciliável com a teoria subjetiva. Mas, como também lhe não é adversa, deve prevalecer, na interpretação, que é tarefa entregue à jurisprudência, a orientação atualmente consagrada na doutrina, que leva à responsabilidade objetivamente considerada, isto é, à teoria do risco administrativo, muito mais equitativa.

Nem teria como concluir-se de outro modo, se a indenização visa a restaurar o equilíbrio rompido em razão do ato que provocou o dano. Veja-se o que, ao propósito, pondera PAUL DUEZ: "Todo prejuízo causado pela empresa pública, prejuízo que se analisa em um cargo público, uma vez que essa empresa não se considere mais como negócio de um soberano todo-poderoso, mas como forma de dar satisfação às necessidades gerais da coletividade, deve, se fere a igualdade dos indivíduos quanto aos encargos públicos, ser reparado, pela outorga à vítima de uma indenização paga pelo patrimônio administrativo: a coletividade, nacional ou local, segundo o caso, assumirá esse encargo. A responsabilidade do poder público visa, pois, ao restabelecimento do equilíbrio econômico e patrimonial inspira-

Cf. supra, nota 22. 
do na idéia de igualdade dos cidadãos perante os encargos públicos, idéia inserta na consciência jurídica moderna". ${ }^{25}$

Muito antes, já se manifestara, no mesmo sentido o nosso AMARO CAVALCÂNTI, como igualmente assinala AGUIAR DIAS. ${ }^{26}$

Ocorrido o dano e inexistindo culpa lato sensu, responde a pessoa jurídica de direito público sem que possa recorrer à ação regressiva contra o agente que tenha praticado o ato causador do dano. A responsabilidade da pessoa jurídica de direito público, em relação ao terceiro que sofreu o dano, é objetiva (risco administrativo), isto é, independentemente de ter sido culposa a ação ou omissão, mas, quanto ao funcionário causador do dano, aplica-se a responsabilidade subjetiva (teoria da culpa). ${ }^{27}$ Quer dizer, havendo prejuízo causado pelo agente de uma pessoa jurídica de direito público, sem que para isso tenha concorrido culposamente a vítima do dano, responde a entidade pública, com base na teoria do risco administrativo, ${ }^{28}$ ainda que se não tenha verificado, em relação ao agente, culpa lato sensu. Se o dano sofrido decorreu de ação ou omissão culposa do funcionário, ainda assim responde perante o lesado a pessoa jurídica de direito público, mas a esta se reserva o direito de regresso, vale dizer, de se ressacir pelo funcionário do quantum da indenização paga, através da competente ação regressiva. Como o funcionário só responde perante a pessoa jurídica de direito público se agiu com dolo ou culpa, relativamente a ele incide a teoria subjetiva (responsabilidade por culpa).

25 La Responsabilité de la Puissance Publique (en dehors du contrat) Paris, 1937, p, 61, apud AGUIAR DIAS, Da Resp. Civil., cit., vol, dehors du contrat), Paris, 1937, p. 61, AMARO CAVALCANTI, Responsabilidad, cit., vol. II, n. ${ }^{0} 210$, p. 222.

ob. e vol. cits. retro, n.o 210 notade Civil do Estado, Rio, 1905, apud AGUIAR DIAS. Para a teoria clássica, năo nota 1.093, ps. 222 e 223.

homem só é responsável păo há responsabilidade sem culpa, provada ou presumida. 0 outrem, dos animais ou das seus atos se cometeu uma falta $\theta$, quanto ao fato de lei a presume contra ou das coisas inanimadas, só existe responsabilidade porque a HENRI LALOU, Traité Pratique de (Cf. excelenté resumo da teoria da culpa feito por n. ${ }^{\circ}$ 122, p. 84. "a admissão de um caso de (Rev. Crit. 1905, p. 279, apud LALOU, ob. e loc. cits.) seria, para o direito civil, de responsabilidade sem culpa seria uma injustiça social; inocente". Em opo

de culpa provada ou presumia, formulou-se outra, que năo mais se baseava na idéia JOSSERAND $\theta$ que assim torna o autor do ato responsével resume: toda atividade que cria para outrem um risco se houve, ou năo, culpa de sua pelo dano que possa causar, sem que se haja de indagar procurar um proveito, é justo que ubi emolumentum, ibi onus que, em contraposição, repare os danos que causa: "Com a teoria do risco, o luiz.

do ato censurado ao pretensiz năo tem mais que perquirir do caráter lícito ou illicito simples problemas objetivos que responsável. As questōes de responsabilidade tornam-se (HENRI LALOU, ob. cit. n o e reduzem à investlgação de um nexo de causalidade" $\mathrm{O}$ risco decorre de uma ${ }^{\circ} 123$, ps. 84 e 85 )

originando-se do perigo intro açăo ou omissăo, independente do conceito de culpa, inclusive em virtude de atuação dos qu vida social por qualquer espécie de atividade, 
8. A vítima, por conseguinte, propõe ação de indenização tão-somente contra a pessoa jurídica de direito público, não se admitindo o litisconsórcio passivo obrigatório, isto é, não se pode obrigar a integrar a ação o servidor que causou o dano, por ação ou omissão, ainda que tenha ele agido com culpa em sentido amplo. Todavia, não se impede que o funcionário, voluntariamente, intervenha nessa demanda como assistente da administração, pois é evidente o seu interesse em que se julgue improcedente a ação, em face da regressiva a que terá de responder perante a entidade pública que nouver sido condenada a indenizar. 29

9. Por efeito da teoria objetiva, quando é indiferente, para o lesado, tenha ocorrido falta funcional ou do serviço, responde a administração pelo dano causado. Se houver culpa do funcionário, este a ressarcirá da indenização paga; inexistindo culpa do agente, a exoneração do dano só poderá verificar-se, total ou parcialmente, se houver ocorrido culpa total ou parcial da vítima. ${ }^{30}$ Também constituem causas excludentes da responsabilidade da pessoa jurídica de direito público, além da culpa da vítima, o caso fortuito ou de força maior, ${ }^{31}$ ou quando se trate de determinados atos de império. ${ }^{32}$

10. A ação regressiva tem como pressuposto a condenação da entidade pública, em sentença transitada em julgado, ${ }^{33}$ a reparar o dano sofrido, e só terá procedência, como esclarecido, se se comprovar que o funcionário agiu com culpa em sentido amplo. ${ }^{34}$

Julgada procedente a ação regressiva contra o funcionário causador do dano e se, na execução da sentença, verificar-se a

29 No mesmo sentido, HELY LOPES MEIRELLES, Direito Administrativo Brasileiro, 2,a ed., Såo Paulo, Revista dos Tribunais, 1966, p. 540.

30 HELY LOPES MEIRELLES, ob. cit., p. 541.

31 Cf. PAUL DUEZ, ob. cit., p. 62, apud AGUIAR DIAS, Da Resp. Civ., cit., vol. II, n.0 210, p. 224.

Os chamados atos de poder público, ou de império, săo os de Governo, os especificos dos Poderes Legislativo e Judiciário, bem como os de polícia (Ct. ROGER BONNARD, Précis de Droit Administratif, 3.a ed., Paris, 1940, p. 136; HENRI LALOU, ob. cit., n. 01.459 , ps. 829 e 830 ).

Há, entretanto, casos em que determinados atos legislativos, jurisdicionais e de polícia, assim como de Governo, podem ocasionar direito a reparaçăo (Ct. LALOU, ob. O vol. cits., n.0 1.470 e segs., ps. 831 e segs.; RENE SAVATIER, ob. e vol. cits., n. ${ }^{\circ} 212$,

33 Ps. 269 - 270 ).

33 Estatuto dos Funcionários, art. 197, $\S 2 .^{\circ}$; Lei n..$^{\circ} .619$, de 28 de abril de 1965, art. 4.ำ, caput.

34 "Para o êxito desta açăo exigem-se dois requisitos: primeiro, que a administraçăo já tenha sido condenada a indenizar a vitima do dano sofrido; segundo, que tenha ficado comprovada a culpa do funcionário no evento danoso. Enquanto para a Administraçăo a responsabilidade independe de culpa, para o servidor a responsabilidade depende de culpa: aquela é objetiva, esta é subjetiva, e se apura pelos critérios gerais do Código Civil" (HELY LOPES MEIRELLES, ob. cit., p. 542). 
inexistência de bens do executado que respondam pelo ressarcimento da indenização paga pela entidade ao terceiro lesado, nada impedirá que também se proceda na forma prevista no art. $97, \S 1 . \circ$ do Estatuto dos Funcionários, que se refere ao dano direto. ${ }^{35}$

11. Com a ação regressiva não se exaure a faculdade punitiva sobre o agente causador do dano, que se a ação ou omissão revestir ilícito penal e disciplinar, poderá responder, ainda, em face do princípio da responsabilidade tríplice e cumulativa ${ }^{36}$, criminal e administrativamente.

A responsabilidade penal abrange os crimes e contravencões imputados ao funcionário, ${ }^{37}$ que tenha agido nessa qua-
lidade. ${ }^{38}$

Ainda que o ilícito penal de que se trate tenha sido considerado, em processo regularmente instaurado e julgado, como não-passível de punição disciplinar, poderá a ação criminal condenatória, dada a independência das instâncias, determinar a pena acessória da perda da função pública, por se julgar cometido o crime com abuso de poder ou violação de dever inerente à função pública. ${ }^{39}$ Também insuscetível o delito de configurar ilícito administrativo, poderá a condenação no juízo criminal determinar a pena acessória da perda da função pública, se se cominar pena de reclusão superior a dois anos ou de detenção por mais de quatro. ${ }^{40}$

12. A decisão judicial no processo-crime, não obstante o princípio da independência das instâncias, pode, em determinados casos, influir na ação de responsabilidade civil, ou no processo disciplinar, trancando definitivamente ambos os procedimentos (civil e disciplinar).

A sentença, no processo penal, pode determinar: a) a condenação criminal do funcionário; b) a sua absolvição, por reconhecer a sentença penal ter sido praticado o ato em estado de necessidade, em legítima defesa, em estrito cumprimento de dever legal ou no exercício regular de direito; c) a absolvição do agente administrativo pela negativa de autoria ou inexistên-

\footnotetext{
35 Desconto em prestaçర̃es mensais năo excedentes da décima parte do vencimento ou

36 Estatuto dos Funcionários, art. 200.

38 Estatuto dos Funcionários, art. 198.

39 Código Penal, art. 68, n. $0^{\circ}$,

40 Código Penal, art. 68, n. ${ }^{\circ} 11$.
}

R. Serv. públ., Brasília, 108 (3) set./dez. 1973 
cia do fato, sem que reste resíduo; d) a absolvição por ausência de culpabilidade penal, e e) a absolvição por insuficiência de provas ou quaisquer outros motivos não-referidos nas alíneas anteriores.

Na primeira hipótese, impõe-se a reparação do dano civil e punição disciplinar; ${ }^{41}$ na segunda e terceira, total irresponsabilidade civil e disciplinar; ${ }^{42}$ na quarta e quinta, não influi a decisão nos procedimentos civil e administrativo. ${ }^{43}$

O princípio, pois, é que, se o fato constitui crime, negada a autoria do funcionário no Juízo Criminal, ou reconhecida qualquer das causas excludentes de culpabilidade referidas no art. 65 do Código de Processo Penal, a absolvição pela sentença penal interfere na ação civil e no processo administrativo, para excluir o servidor de qualquer responsabilidade, quer civil (Cód. Civ., art. 1.525), quer disciplinar. Nas outras hipóteses, é livre a ação disciplinar, a despeito da absolvição criminal, o que igualmente possibilitará a responsabilidade civil.

Prescrita a punibilidade do ilícito penal constitutivo também de ilícito administrativo, não se poderá exercer a ação disciplinar, ${ }^{44}$ o mesmo não ocorrendo, entretanto, com a responsabilidade civil, que, por ser ação pessoal, prescreve em vinte anos. ${ }^{45}$

13. "A responsabilidade administrativa" - diz o Estatuto dos Funcionários - "resulta de atos ou omissões no desempenho do cargo ou função". ${ }^{46}$

41 Cód. Proc. Penal, art. 63; Estatuto dos Funcionários, art. 200.

42 Cód. Proc. Penal, art. 65; Cód. Civ., art. 1.525, 2.a parte.

"Se a justiça criminal nega a existência do fato, năo pode subsistir a pena disciplinar imposta pela autoridade administrativa com base nesse mesmo fato" (R.E. n. ${ }^{\circ}$ 39.505-DF, in D.J. de 26-3-62, Apenso, p. 70, apud WALDYR DOS SANTOS, O Regime Disciplinar do Servidor Público no Judiciário, DASP, 1971, p. 17).

43 Cód. Proc. Penal, arts, 66 e 67. Veja-se, também, a seguinte Súmula do Supremo Tribunal Federal: "18. Pela falta residual, não compreendida na absolvição pelo juizo criminal, é admissivel a punição administrativa do servidor público (apud aut. e ob. cits., p. 17).

E ainda WALDYR DOS SANTOS quem nos fornece os seguintes acórdãos:

- "Absolvição criminal. Residuo. Mantida a demissăo porque năo excluida a possibilidade de ter havido resíduo para a puniçăo administrativa" (R.E. n.० 55.101-SP, in D.J. 11-8-65, p. 1.932, e E.R.E. n. ${ }^{\circ} 55.101-S P$, in D.J. 20-11-67, p. 3.844, apud aut. $\theta$ ob. cit., p. 18).

- ... "a jurisdiçăo administrativa disciplinar năo fica prejudicada pela sentença absolutória do Julzo Criminal, se este năo negou a ocorrência do fato incriminador, atribuldo ao funcionário, nem a sua autoria" (R.E. $45.766-$ GB, in D.J. 11-8-61, p. 1.609, id, ibid, loc. cit.)

44 Estatuto dos Funcionários, art. 213, parágrafo único.

45 Cód. Civ., art. 177.

46 Estatuto cit., art. 199. 
O Direito Disciplinar é inteiramente autônomo em relação ao Direito Penal, não estando mesmo, ao contrário deste último, adstrito ao princípio da reserva legal, prescindindo, por esse efeito, de prévia configuração da falta. ${ }^{47}$ Assim é que, por exemplo, não obstante a imprecisão e generalidade da expressão "falta grave", não-conceituada na lei, pode ela originar pena administrativa (suspensão ou multa). 48

Por esse efeito, pode dizer-se, de um modo geral, que as punições administrativas, com exclusão das expulsivas, estão sujeitas a um certo arbítrio ${ }^{49}$ da autoridade a quem incumbe a ação repressiva, adstrita esta, tão-somente, aos princípios gerais de direito.

14. O ilícito administrativo, quando pode configurar pena de suspensão por mais de trinta dias, destituição de função, demissão e cassação de aposentadoria e disponibilidade terá de ser apurado em processo administrativo em que se assegure ao acusado ampla defesa. ${ }^{50} \mathrm{~A}$ repreensão, multa e suspensão por prazo até trinta dias prescindem de instauração de inquérito administrativo, podendo ser aplicadas, desde logo, pela autoridade a quem incumbe a ação repressiva.

$O$ processo disciplinar compreende três fases ${ }^{51}$ fundamentais: a da instrução, através da qual se arrolam os elementos de prova da existência dos fatos constitutivos do ilícito administrativo imputado ao funcionário; a da defesa, em que o acusado, com amplitude de ação, pode demonstrar a inexistência do ilícito de que é acusado, e, finalmente, a de decisão ou julgamento, em que a autoridade a quem compete a ação disciplinar examina os elementos arrolados na instrução e os argumentos e provas oferecidos pela defesa para concluir, ou pela cominação de penalidade administrativa, ou pela isenção de punibi-

47 Cf. nossos Estudos de Direito Administrativo, Rio, Imprensa Nacional, vol. I, 1960, ps. 376 e segs; vol. II, 1965, pgs. 276 e segs., e mais os autores e obras ali citados.
Ao propósito, assim se

Administrativo, Froitas Bastos, 1943, TITO PRATES DA FONSECA (Liçōes de Direito MARCELO CAETANO, năo existe, a , n. ${ }^{\circ} 114$, p. 191): "Na infraçăo disciplinar, ensina legal - a prévia definiçăo do ato contrário do que acontece no crime, um elemento da autoridade, a quem a lei confere ou omissão como ilicito e punivel. Depende, pois, como infraçăo desse gênero, $e$ a o poder punitivo disciplinar o qualificar certo ato necessário ter sempre em vista a definicâaçåo da responsabilidade. Mas, para isso, é plificação, a lei estabelece". Mas, acrescenta genérica legal e os critérios que, por exempenas expulsivas não se aplicam, sem denta TITO PRATES (id., ibid., loc. cit.), "as

48 Estatuto cit., art. 205 e seu parágrafo determinaçăo legal".

49 ..."o processo administrativo parágrafo único.

poder discricionário do Executivo" (TIT) tem a sua decisão abrangida no campo do

50 Estatuto cit., art. 217 e seu parágrafo úniCATES DA FONSECA, ob. cit., n.o 122, p. 206).

51 da Constituição Federal, na redaçăo em vigor., quanto à demissăo, o art. 105, n.o II,

Funcionários Públicos Interpretado, 3 . A A. CONTREIRAS DE CARVALHO, in Estatuto dos

d., Freitas Bastos, 1964, vol. II, ps. 218 e segs. 
lidade, decorrente da não-configuração de qulaquer falta disciplinar.

O Estatuto dos Funcionários, em todo o seu Título V, dispõe sobre o processo administrativo, estabelecendo prazos e demais normas desse procedimento (Capítulo I), bem como sobre a revisão desse processo (Capítulo II), quando se aduzem fatos ou circunstâncias suscetíveis de justificar a inocência do requerente. ${ }^{52}$

A revisão, no caso de funcionário falecido ou desaparecido, poderá ser requerida por qualquer das pessoas que constem do seu assentamento individual, ${ }^{53}$ correndo ém apenso ao processo originário. ${ }^{54}$

Se for julgada procedente a revisão, a penalidade imposta é anulada, restabelecendo-se ex tunc todos os direitos atingidos pela sanção disciplinar. ${ }^{55}$ 
